\title{
Effect of inhaled morphine on the development of breathlessness during exercise in patients with chronic lung disease
}

\author{
Roland Leung,* Prudence Hill, Jonathan Burdon
}

\begin{abstract}
Background - Inhaled morphine has previously been shown to increase exercise endurance in patients with chronic lung disease. A similar study was performed to determine whether inhaled morphine reduces the sensation of breathlessness in this group of patients.
\end{abstract}

Methods - A randomised double blind study on the effect of nebulised morphine on both exercise induced breathlessness and maximum achievable power output using isotonic saline as a control was performed in 10 patients with stable chronic lung disease. Each subject performed a progressive exercise test (Jones' stage I) on an electrically braked cycle ergometer. The work load was increased by 10 watts per minute and subjects exercised to exhaustion. At the end of each minute of exercise patients were asked to rate their degree of breathlessness according to a modified Borg scale. All subjects were randomised to receive either inhaled morphine sulphate $1 \mathrm{mg} / \mathrm{ml}(5 \mathrm{ml})$ or isotonic saline $(5 \mathrm{ml})$ by wet nebulisation. The effect of morphine and saline on the achieved exercise capacity and the development of breathlessness during exercise was tested on separate days.

Results - The mean dose of morphine inhaled was $1 \cdot 24 \mathrm{mg}$. There was no difference in maximum power output achieved, minute ventilation at maximum power output, nor the degree of breathlessness at maximum power output between the groups treated with morphine and placebo. The degree of breathlessness was related to the power output achieved during exercise by a power function relationship (mean $r$ : morphine $=0 \cdot 86$, saline $=0 \cdot 87$ ). However, there was a wide variation in the sensation for any given power output in both groups. There was no difference in the group mean slopes (morphine $=1 \cdot 15$, saline $=1 \cdot 00$ ) or intercepts (morphine $=0 \cdot 07, \quad$ saline $=$ $0 \cdot 15$ ) in this relationship between the morphine and saline treatment groups.

Conclusions - In patients with severe chronic lung disease inhaled morphine in the doses used in this study does not relieve exercise induced breathlessness nor does it increase maximum power output achieved during progressive exercise.

(Thorax 1996;51:596-600)

Keywords: inhaled morphine, exercise endurance, breathlessness.
Breathlessness is a common and distressing symptom of chronic lung disease but, despite maximal treatment, many patients continue to experience persistent and disabling symptoms. In recent years there have been significant advances in our understanding of the nature of this symptom but, despite increases in knowledge, the underlying mechanisms by which the symptom of breathlessness is generated have yet to be elucidated. In an attempt to modify the sensation of breathlessness or its perception many drugs including dihydrocodeine,${ }^{1-3}$ morphine, ${ }^{4-6}$ and diazepam ${ }^{78}$ have been tested. These studies have, however, led to conflicting and inconclusive results.

Young et $a l^{6}$ recently examined the effect of inhaled morphine sulphate on exercise endurance in patients with chronic lung disease and found an increase in endurance in the morphine treated group. This result could be interpreted to show that inhaled morphine relieves breathlessness even though breathlessness per se was not measured. In order to clarify this potential misconception and to determine if small but safe doses of morphine might be associated with relief of breathlessness, we undertook a similar double blind, placebo controlled study with the express aim of determining the effect of modest but safe doses of inhaled morphine sulphate on exercise induced breathlessness in a similar group of patients.

\section{Methods}

SUBJECTS

Ten subjects with stable chronic lung diseases recruited from the respiratory outpatient clinic were studied (table 1). Patients with carbon dioxide retention and ischaemic heart disease were excluded. All were using inhaled steroids and three were on maintenance oral steroids. No patient had been taking narcotic drugs in the previous three months and none had any previous experience with sensory testing.

PROTOCOL

Each subject performed progressive exercise tests on two separate days following a standard Jones' stage 1 protocol. ${ }^{9}$ On each day the subject performed a baseline exercise test to ensure familiarity with the equipment and required measurements. This was followed by a $90 \mathrm{~min}-$ ute rest period. The subjects were then randomised to receive either nebulised isotonic saline $(5 \mathrm{ml})$ or nebulised morphine sulphate

15 Noved to authors

Revised version received

Accepted for publication

23 December 1995 
Table 1 Patient characteristics

\begin{tabular}{lllllll}
\hline $\begin{array}{l}\text { Patient } \\
\text { no }\end{array}$ & $\begin{array}{l}\text { Age } \\
\text { (years) }\end{array}$ & Sex & Diagnosis & $\begin{array}{l}\text { FEV }(l) \\
(\% \text { pred })\end{array}$ & $\begin{array}{l}\text { VC(l) } \\
(\% \text { pred) }\end{array}$ & $\begin{array}{l}\text { Nebulised } \\
\text { morphine (mg) }\end{array}$ \\
\hline 1 & 51 & M & COPD & $1 \cdot 85(45)$ & $4 \cdot 75(88)$ & $3 \cdot 88$ \\
2 & 67 & F & COPD & $1 \cdot 00(55)$ & $1 \cdot 20(52)$ & $3 \cdot 88$ \\
3 & 55 & M & COPD & $0 \cdot 95(29)$ & $2 \cdot 35(55)$ & $4 \cdot 13$ \\
4 & 62 & M & DILD & $1 \cdot 70(58)$ & $1 \cdot 80(47)$ & $2 \cdot 65$ \\
5 & 66 & M & COPD & $1 \cdot 15(37)$ & $2 \cdot 70(65)$ & $3 \cdot 42$ \\
6 & 71 & M & COPD & $0 \cdot 80(35)$ & $1 \cdot 65(54)$ & $4 \cdot 11$ \\
7 & 54 & F & COPD & $0 \cdot 75(33)$ & $1 \cdot 65(60)$ & $3 \cdot 74$ \\
8 & 69 & COPD & $0 \cdot 60(38)$ & $1 \cdot 50(73)$ & $1 \cdot 06$ \\
9 & 65 & M & COPD & $1 \cdot 60(59)$ & $2 \cdot 40(67)$ & $3 \cdot 81$ \\
10 & 61 & F & COPD & $1 \cdot 30(59)$ & $2 \cdot 50(92)$ & $3 \cdot 42$ \\
\hline
\end{tabular}

COPD $=$ chronic obstructive pulmonary disease $;$ DILD = diffuse interstitial lung disease; $\mathrm{FEV}_{1}=$ forced expiratory volume in one second; $\mathrm{VC}=$ vital capacity

( $5 \mathrm{mg}$ in $5 \mathrm{ml}$ isotonic saline) in a double blind fashion. The dose of morphine was chosen to match that used by Young et $a l^{6}$ as closely as possible and to avoid any potential central respiratory depressant effects. The inhalation was delivered by a Hudson Up-Draft II jet nebuliser and face mask driven by oxygen at a rate of $6 \mathrm{l} / \mathrm{min}$ for 12 minutes. The nebuliser was weighed before and after inhalation and the amount of morphine inspired was calculated by assuming an inspiratory time of one third of the respiratory cycle. The exercise test was conducted 15 minutes after the inhalation. On a separate day the same exercise/inhalation regimen was repeated with the other test solution. The randomisation of test solution was designed to ensure that half the subjects received the placebo as their first test solution and the other half morphine first, thus avoiding an order effect.

EXERCISE TEST

The exercise test was performed on a Siemens EM840 electrically braked cycle ergometer following a modified Jones' stage 1 protocol. ${ }^{9}$ The workload was increased by 10 watts at the end of each minute of exercise and the patient exercised to exhaustion. The subject inhaled $100 \%$ oxygen throughout the test because, in doing so, we believed that they would be able to exercise for a longer time and thus would be able to provide more sensory data. Respiratory rate, minute ventilation (Morgan ventilation monitor), electrocardiography (Cardiofax $6543 \mathrm{~A})$, and percutaneous haemoglobin oxygen saturation (Nellcor oximeter) were monitored continuously throughout the experimental procedure and recorded on a chart recorder (Hewlett Packard 7754A). Immediately before the commencement of the test, at the end of each minute of exercise, and at the end of the test the subjects were asked to rate the degree of breathlessness experienced according to a modified Borg scale. ${ }^{10}$ The Borg scale is a category scale in which words describing increasing symptoms of breathlessness are anchored to numbers between 0 and 10 . Each subject was asked to rate the degree of breathlessness by selecting a number whose words most appropriately described the sensation of breathlessness at that particular time. Subjects were free to select whole numbers or fractions of numbers as they desired, and we were careful to instruct them to rate their symp- tom of breathlessness and to ignore other symptoms such as throat irritation. Spirometric tests were performed before and after exercise to exclude any potential effect on lung mechanics by the exercise test itself - for example, exercise induced bronchoconstriction - which could result in an increase in breathlessness.

\section{DATA ANALYSIS}

The relationship between the Borg score and the power outputs at which they were measured was found to follow a power function relationship in all subjects studied. Intercepts and slopes were calculated for each individual and Borg scores at standard power outputs, selected to lie within the measured range, were determined by interpolation. Group mean results were expressed as the arithmetic mean of the Borg scores at these particular power outputs. Two way analysis of variance was used to determine the significance between the study groups. Statistical differences between the measured indices at maximum power output were compared using the Wilcoxon rank sum test.

\section{Results}

The characteristics of the 10 patients (six men) are summarised in table 1 . There were nine patients with chronic obstructive pulmonary disease (COPD) with a mean forced expiratory volume in one second $\left(\mathrm{FEV}_{1}\right)$ of $1.12 \mathrm{l}$, and one with pulmonary fibrosis with a vital capacity (VC) of 1.81 . Their mean age was 62 years (range 51-71). The mean dose of morphine nebulised was $3.79 \mathrm{mg}$ with a calculated mean inhaled dose of $1.25 \mathrm{mg}$ assuming that $33 \%$ of the dose was inhaled (see Methods above). There were no significant changes in spirometric parameters before and after exercise on each of the test days and between the two test days in all subjects.

Patients exercised to exhaustion and achieved a mean maximum power output of 58 watts following inhaled morphine and 55 watts after inhaling saline (table 2). Mean values for minute ventilation, heart rate, and Borg score at maximum power output are shown in table 2 . There was no statistically significant difference between the morphine and saline pretreatment groups for any of the parameters measured (Wilcoxon rank sum test).

Breathlessness as indicated by the Borg score (S) increased as the power output (PO) achieved during exercise increased and was significantly related by a power function in both

Table 2 Mean (SD) maximum power output (POmax), ventilation ('VEmax), heart rate and Borg score achieved during exercise

\begin{tabular}{llc}
\hline & \multicolumn{2}{l}{ Pretreatment group } \\
\cline { 2 - 3 } & Morphine & Saline \\
\hline POmax (watts) & $58(28)$ & $55(26)$ \\
VEmax (litres) & $23(9)$ & $27(7)$ \\
Heart rate (max)/min & $99(28)$ & $123(28)$ \\
Borg score (max) & $8 \cdot 7(2 \cdot 2)$ & $9 \cdot 7(1 \cdot 0)$ \\
\hline
\end{tabular}

No significant difference was seen in any of the parameter measured (Wilcoxon rank sum test). 


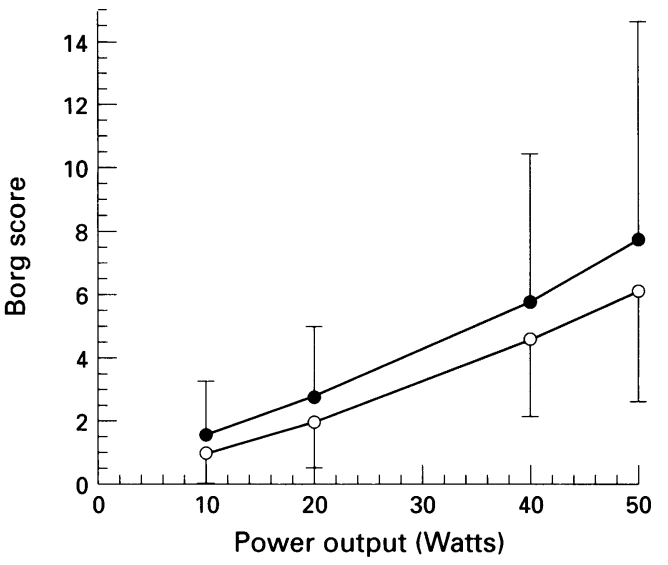

Effect of saline (O) and morphine ( $\bigcirc)$ on relationship between breathlessness (Borg score) and power output during incremental exercise.

study groups (morphine: $\mathrm{S}=0 \cdot 07 \mathrm{PO}^{1 \cdot 15}$, mean $r=0 \cdot 86$; saline: $\mathrm{S}=0 \cdot 15 \mathrm{PO}^{1 \cdot 0}$, mean $r=0 \cdot 87$ ). There was a wide variation in the sensation for any given power output in both groups (figure); no significant difference in this relationship was seen between the two groups (two way analysis of variance).

\section{Discussion}

Breathlessness and exercise limitation are commonly experienced by patients with advanced lung disease. In this group of patients Young et $a l^{6}$ have shown that the use of low dose inhaled morphine increases exercise endurance. We have extended this study to determine whether inhaled morphine reduces the sensation of exercise breathlessness. Our results show that the inhalation of morphine does not reduce the sense of breathlessness in patients with severe chronic lung disease and, furthermore, does not increase the maximum power output achieved during progressive exercise.

In studying the effect of low dose inhaled morphine on exercise induced breathlessness we adopted a protocol that allowed us to maximise the number of assessments of breathlessness (Borg scores) that could be obtained. For this reason power output was increased progressively at a rate of 10 watts per minute rather than employing larger increments or a quasi steady state procedure. Supplemental oxygen was given in order to delay the development of exercise induced hypoxaemia severe enough to lead to early termination of the test. This maximised the number of breathlessness assessments (Borg scores) obtained. With these modifications an average of seven Borg scores were achieved per subject, thus ensuring a large enough number of data points to assess the relationship between these two indices adequately.

The pathophysiological basis of the sensation of breathlessness remains incompletely understood and is discussed elsewhere in detail. ${ }^{11}$ Despite some advances in the knowledge of the perception and genesis of breathlessness, these have had little impact on therapy. In clinical practice this often distressing symptom demands relief. The treatment of breathlessness is most effective when the primary cause can be identified and modified but, in those conditions in which treatment currently has little to offer, it is intuitively attractive to attempt to manipulate the symptom of breathlessness itself.

Over the years many attempts have been made in this regard and, although there have been some claims of success, none has achieved more than an alteration of the underlying mechanical events which subserve the symptom of breathlessness - for example, ventilatory drive, the pattern of breathing, etc. It is our view and has been published elsewhere that claims that these studies show that breathlessness per se has been reduced cannot be upheld. ${ }^{12}$

Opiates have long been popular treatment for the alleviation of breathlessness in patients with respiratory disease. However, they have not achieved widespread usage largely because of potential side effects such as respiratory depression and addiction. There are a number of possible mechanisms by which nebulised morphine may alleviate the sensation of breathlessness a short time after inhalation. Firstly, morphine may reduce the degree of anxiety experienced by a particular subject and hence the degree of breathlessness; secondly, perceptual responses to the incoming neural traffic or its central interpretation may be blunted; and, finally, nebulised morphine may alleviate the sensation of breathlessness a short time after inhalation by direct local action on peripheral neural receptors in small airways. Opioid peptide-like activity has been detected in bronchial mucosa cells ${ }^{13}$ and thus morphine may be in a position to modify the perception of breathlessness in the same way as it alters the perception of pain. In our study we believe that any anxiety experienced by our subjects was minimal. They were all well known to us having attended our department for some years and had a good understanding of their condition and the tests to be performed. The mean inhaled dose of morphine was $1.24 \mathrm{mg}$ in our study which was comparable to that used by Young $e t a l^{6}$ and was sufficiently low for it to be unlikely to have caused any central depression that could have resulted in a reduction in breathlessness. Furthermore, as the surface area of the small airways is large, there remains some doubt as to whether a sufficient amount of the drug was delivered to achieve any direct effect on peripheral neural receptors in these airways. It is also possible that the dose of morphine used in this study was too small to achieve any direct effect. We used $5 \mathrm{mg}$ of morphine delivered by wet nebulisation via a jet nebuliser and face mask. New nebulisers were used and the amount of morphine delivered to the airway was calculated from the difference in weights before and after nebulisation multiplied by 0.33 to account for that volume blown away (assumes that inspiration was one third of the respiratory cycle). Other losses - for example, condensate in the face mask - are likely to be small and have been ignored. Future studies using varying con- 
centrations of nebulised morphine in higher doses to assess breathlessness and exercise endurance are needed to determine whether a dose dependent response exists.

Light et $a l^{4}$ used oral morphine $(0.8 \mathrm{mg} / \mathrm{kg})$ in patients with severe chronic airflow obstruction and showed that exercise capacity was increased and breathlessness, assessed using a modified Borg scale, significantly decreased. The reduction in breathlessness in this study was achieved at the expense of an increase in arterial carbon dioxide tension, a reduction in ventilatory drive $\left(P_{0 \cdot 1}\right)$, and was thought by the authors to be due to a combination of lowered ventilatory requirements for a given work load and also to altered perception. However, in a subsequent study ${ }^{5}$ where arterial blood gases remained stable, breathlessness and exercise tolerance were unchanged following the administration of diamorphine. This result suggests that the reduction in breathlessness in Light's earlier study ${ }^{4}$ is likely to be solely due to changes in ventilatory drive and not specifically to a modification in the perceptive process. Light et $a l^{4}$ used an incremental exercise protocol similar to the one used in our study and that of Masood et $a l^{14}$ and found a beneficial effect from oral morphine, yet no benefit was observed with inhaled morphine by either Masood et $a l^{14}$ or ourselves. Eiser et $a l^{5}$ used an endurance protocol similar to that of Young et $a l^{6}$ but found no effect from oral morphine and yet Young et $a l^{6}$ found a beneficial effect from inhaled morphine. These results at first seem conflicting except that those studies which found no change in the mechanical and chemical influences on ventilation from their morphine regimen also found no change in the sensation of breathlessness.

Dihydrocodeine administered orally before exercise has also been shown to reduce dyspnoea ${ }^{1}$ by $20 \%$ (assessed using a visual analogue scale) in a similar group of patients. Minute ventilation and oxygen consumption were reduced in this study despite an increase in exercise capacity. Similar findings have also been reported following the long term administration of dihydrocodeine. ${ }^{2}$ Endogenous opiates may also play a part in the perception and/or modification of breathlessness and this concept is supported in general terms by the observation that naloxone restored blunted ventilatory responses in patients with chronic airflow obstruction. ${ }^{15}$

Other drugs, in particular the benzodiazepines, have been studied for their effect on the relief of breathlessness. Enthusiasm for the therapeutic use of diazepam was engendered by the initial report of Mitchell-Heggs et $a l^{7}$ who reported a "striking" reduction in breathlessness (subjectively assessed) in four men with the "pink puffer syndrome" when treated with this drug. This finding has not been sustained in other studies. ${ }^{816}$ This syndrome (severe airflow obstruction, relatively preserved gas exchange, and severe breathlessness) probably merges with those subjects considered to have disproportionate breathlessness by Burns and Howell. ${ }^{17}$ When this latter group were contrasted with subjects with appropriate breathlessness, there appeared to be increased stress, anxiety, and hyperventilation. It is probable therefore that the action of diazepam in relieving breathlessness in a specific subgroup is related to its anxiolytic properties although it also causes respiratory depression (decreased ventilatory drive) as shown by reductions in carbon dioxide sensitivity. Promethazine was also studied by Woodcock $e t a l^{8}$ and found to reduce breathlessness without altering lung function, but these results were not supported in a subsequent study. ${ }^{16}$ Other anxiolytics ${ }^{1819}$ and the prostanoid indomethacin ${ }^{20}$ have been studied with variable results.

The modification of the perception of breathlessness by pharmacological means in the pursuit of relieving symptoms has received much attention. At the present time the results of these studies have not yielded any specific answers nor provided any clear direction with respect to the specific suppression of the symptom of breathlessness at a central level. Those studies which conclude that breathlessness can be reduced by pharmacological means need to be interpreted with great care because in almost all cases the reduction in breathlessness can be explained in terms of changes in ventilatory drive and/or other aspects of the mechanical or chemical control of breathing. Furthermore, a marked placebo effect has been demonstrated in some patients with airflow obstruction. ${ }^{21}$ These findings, in addition to the significant incidence of potentially serious side effects, imply that the routine prescription of drugs in pursuit of the relief of breathlessness cannot be recommended at present.

In conclusion, we have shown that the inhalation of morphine sulphate does not relieve exercise induced breathlessness nor does it increase maximum achievable power output during exercise in patients with severe chronic lung disease. Inhaled morphine may theoretically block the peripheral neural receptors in small airways important in mediating the sensation of breathlessness but, if so, then it is ineffective in the doses used in this study.

The authors are indebted to $\mathrm{Mr}$ John Martin and Dr John Reeves for advice and technical assistance and to Dr John Santamaria for statistical help.

1 Woodcock AA, Gross ER, Gellert A, Shah S, Johnson $M$, Geddes DM. Effects of hydrocodeine, alcohol, and caffeine on breathlessness and exercise tolerance in patients with chronic obstructive lung disease and normal patients with chronic obstructive lung disease
blood gases. $N$ Engl f Med 1981;305:1611-6.

2 Johnson MA, Woodcock AA, Geddes DM. Dihydrocodeine for breathlessness in "pink puffers". BMF 1983;286:675-7. 3 Stark RD, Morton PB, Sharman P, Percival PG, Lewis JA. Effects of codeine on the respiratory responses to exercise in healthy subjects. Br $\mathcal{F}$ Clin Pharmacol 1983;15:355-9. 4 Light RW, Muro JR, Sato RI, Stansbury DW, Fischer CE, Brown SE. Effects of oral morphine on breathlessness and exercise tolerance in patients with chronic obstructive pulmo tory disease. Am Rev Respir Dis 1989;126:126-33. pulmonary disease. Am Rev Respir Dis 1989;126:126-33. lack of effect on dyspnoea and exercise tolerance in the "pink puffer" syndrome. Eur Respir f 1991;4:926-31.

6 Young I, Daviskas E, Keena VA. Effect of low dose nebulised morphine on exercise endurance in patients with chronic morphine on exercise endurance in pa

7 Mitchell-Heggs P, Murphy K, Minty K, Guz A, Patterson SC, Minty PS, et al. Diazepam in the treatment of dyspnoea in the "pink puffer" syndrome. $Q \mathcal{F}$ Med 1980;49: 9-20.

8 Woodcock AA, Gross ER, Geddes DM. Drug treatment of breathlessness: contrasting effects of diazepam and promethazine in pink puffers. $B M F$ 1981;283:343-6.

9 Jones NL, Campbell EJM. Clinical exercise testing. Philadelphia: WB Saunders, 1982. 
10 Borg G. Subjective effort and physical activities. Scand $\mathcal{f}$ Rehabil Med 1978;6:108-13.

11 Killian KJ, Campbell EJM. Dyspnoea. In: Roussos C, Macklem PT, eds. The thorax. Part B. Lung biology in health and disease.

12 Burdon JGW, Pain MCF, Rubinfeld AR, Nana A. Chronic lung disease and the perception of breathlessness - a clinical perspective. Eur Respir f 1994;7:1342-9.

13 Bostwick DG, Null WE, Holmes D, Weber E, Barchas JD, Bensch KG. Expression of opioid peptides in tumours. $N$ Engl f Med 1987;317:1439-43.

14 Masood AR, Reed JW, Thomas SHL. Lack of effect of inhaled morphine on exercise-induced breathlessness in chronic obstructive pulmonary disease. Thorax 1995;50; 629-34.

15 Santiago TV, Remolina C, Scoles V, Edelman NH. Endorphins and the control of breathing. $N$ Engl F Med 1981; 304:1190-5.

16 Stark RD, Gambles SA, Lewis JA. Methods to assess breathlessness in healthy subjects: a critical evaluation and ap- plication to analyse the acute effects of diazepam and promethazine on breathlessness induced by exercise or by exposure to raised levels of carbon dioxide. Clin Sci 1981; 61:429-39.

17 Burns BH, Howell JBL. Disproportionately severe breathlessness in chronic bronchitis. $Q \mathcal{F}$ Med 1969;38:277-94. 18 O'Neill PA, Morton PB, Stark RD. Chlorpromazine - a specific effect on breathlessness? Br f Clin Pharmacol 1985; 19:793-7.

19 Man GCW, Hsu K, Sproule BJ. Effect of alprazolam on exercise and dyspnoea in patients with chronic obstructive pulmonary disease. Chest 1986;90:832-6.

20 O'Neill PA, Stark RD, Morton PB Do prostaglandins have a role in breathlessness? Am Rev Respir Dis 1985;132: $22-4$.

21 Noseda A, Schmerber J, Prigogine T, Yernault JC. Perceived effect on shortness of breath of an acute inhalation of saline or terbutaline: variability and sensitivity of an analogue scale in patients with asthma or COPD. Eur Respir f 1992;5:1043-53. 